УДК 661.183.2,620.181.4

\title{
СИНТЕЗ ПОРИСТЫХ МЕТАЛЛ-УГЛЕРОДНЫХ МАТЕРИАЛОВ НА ОСНОВЕ ДРЕВЕСИНЫ БЕРЕЗЫ, МОДИФИЦИРОВАННОЙ ХЛОРИДОМ ЦИНКА И ФЕРРОЦЕНОМ
}

\author{
(C) С.И. Цьианова*, А.М. Жижаев, Г.Н. Бондаренко, О.Ю. Фетисова
}

\author{
Институт химии и химической технологии, Академгородок, 50/24, \\ Красноярск, 660036 (Россия), e-mail: light@icct.ru
}

Проведен синтез пористых металл-углеродных материалов из опилок древесины, модифицированных хлоридом цинка и ферроценом при различных температурах. Установлено, что модификаторы смещают процессы разложения древесины в низкотемпературную область и интенсифицируют процессы пиролиза в высокотемпературной области. Добавка ферроцена в образец приводит к появлению дополнительной стадии интенсивного разложения образца при температуре $750{ }^{\circ} \mathrm{C}$.

Получены пористые углеродные продукты с высокой удельной поверхностью до $1100 \mathrm{~m}^{2} / \Gamma$ при карбонизации образцов до $400{ }^{\circ} \mathrm{C}$, как с одним модификатором $\left(\mathrm{ZnCl}_{2}\right)$, так и двумя $\left(\mathrm{ZnCl}_{2}, \mathrm{Fe}\left(\mathrm{C}_{5} \mathrm{H}_{5}\right)_{2}\right)$. Повышение температуры до $800{ }^{\circ} \mathrm{C}$ приводит к уменьшению удельной поверхности продукта, при этом продукт из древесины с добавкой $\mathrm{ZnCl}_{2}$ имеет удельную поверхность $606 \mathrm{~m}^{2} / \Gamma$, а продукт из древесины из древесины с добавками $\mathrm{ZnCl}_{2}$ и $\mathrm{Fe}\left(\mathrm{C}_{5} \mathrm{H}_{5}\right)_{2}-932 \mathrm{~m}^{2} / \Gamma$. Установлено, что раскрытие пористой структуры продукта в процессе карбонизации модифицированных образцов происходит в основном за счет удаления водорастворимых веществ из низкотемпературных продуктов и высокотемпературных процессов пиролиза.

Выявлены особые текстурные формы углеродного продукта, полученного из модифицированного сырья с двумя реагентами. Показано, что добавка ферроцена в исходную смесь приводит к образованию усеченных конусообразных гексагональных кристаллитов на поверхности продукта, карбонизованного при $400{ }^{\circ} \mathrm{C}$. Предполагается, что рост подобных кристаллитов обусловлен координационным взаимодействием ферроцена с лигниноцеллюлозным полимером и ионом цинка.

Ключевые слова: синтез, пористый металл-углеродный материал, древесина березы, ферроцен, хлорид цинка, морфология

\section{Введение}

Разработка новых методов переработки лигниноцеллюлозного сырья и отходов лесной, деревообрабатывающей промышленности в пористые углеродные материалы, которые находят широкое применение в качестве каталитических подложек, аккумуляторных электродов, конденсаторов, для хранения газов, а также в биомедицинской инженерии, является важной задачей [1-4]. В то же время идет активный поиск новых инициирующих систем для создания новых композиционных материалов, способных влиять на реакционную способность как исходных, так и образующихся в процессе термопревращения веществ [5, 6]. При этом осо-

Цыганова Светлана Ивановна - кандидат химических наук, старший научный сотрудник лаборатории процессов синтеза и превращения углеводородов, e-mail: light@icct.ru

Жижаев Анатолий Михайлович - кандидат технических наук, заведующий лабораторией рентгеновских и спектральных методов анализа

Бондаренко Галина Николаевна - научный сотрудник лаборатории рентгеновских и спектральных методов анализа

Фетисова Ольга Юрьевна - кандидат химических наук, старший научный сотрудник лаборатории процессов синтеза и превращения углеводородов бое внимание уделяется изучению инициирующих систем, в состав которых, наряду с традиционными инициаторами (кислоты Льюиса), входят металлоцены [6-11], которые не только способны активно генерировать радикалы в энергетически выгодном режиме, регулировать процессы, но и могут непосредственно влиять на формирование макромолекул. Стабильность и врожденная электрохимическая чувствительность ферроцена и его производных позволяют создавать на их основе материалы, используемые

\footnotetext{
* Автор, с которым следует вести переписку.
} 
в биомедицине в качестве маркеров и лечения различных болезней $[10,12]$. G. Gasser с соавт. [13, 14] показали, что ферроцен как редокс-активное соединение позволяет электрохимически определелить не только катионы, анионы, но и нейтральные молекулы типа барбитуратов и производных мочевины. В работе Y.J. Chong с соавт. [15] выявлено, что модифицированные ферроцильные сопряжения могут быть использованы как сигнальные пробы для определения нуклеиновых кислот с помощью водородного связывания. Авторы работы [7] сообщают о синтезе металлоцен-углеродных композитов на основе углеродных нанотрубок и полифенилферроцена, которые обладают необычно высокой емкостью $\left(1452 \mathrm{~F} \mathrm{~g}^{-1}\right)$ и энергетической плотностью $\left(79,5 \mathrm{~W} \mathrm{~h} \mathrm{~kg}^{-1}\right)$ и могут быть использованы в качестве суперконденсаторов.

Современные традиционные технологии получения пористых углеродсодержащих материалов из растительных полимеров базируются на физической или химической активации $[1,16-18]$. Физическая активация включает две основные стадии: коксование без доступа воздуха при $500-700{ }^{\circ} \mathrm{C}$ с получением кокса и термообработку в присутствии окислителя при $700-1000{ }^{\circ} \mathrm{C}$. Химическая активация проводится в одну стадию карбонизации углеродного предшественника, в который вводится химический реагент, что сокращает продолжительность процесса, снижает температуру и потери на газификацию. Механизм разложения лигниноцеллюлозного материала под действием кислот Льюиса давно и широко изучается многими исследователями, хотя до сих пор остается много вопросов $[1,16,17]$. Исследований же по термопревращению лигниноцеллюлозного материала, модифицированного кислотами Льюса и ферроценом, в литературе нами не найдено. Хотя известно, что металлоорганические добавки, в отличие от кислот Льюиса, значительно влияют на рост полимерной цепи, будучи введенными в полимеризационную смесь в количествах, соизмеримых с концентрацией инициатора (0,1-0,5 мол.\% по отношению к мономеру) [6].

В ранних работах мы исследовали термохимическое превращение древесины, МКЦ, модифицированных кислотами Льюиса $\left(\mathrm{ZnCl}_{2}, \mathrm{H}_{3} \mathrm{PO}_{4}\right)$, и выявили закономерности и особенности их синтеза $[18,19]$. В частности, отмечается, что формирование пористой структуры наблюдается при температурах выше $600{ }^{\circ} \mathrm{C}$, а дополнительная водная обработка карбонизата раскрывает высокопористую структуру образца, получаемого при $400{ }^{\circ} \mathrm{C}$. Двойное модифицирование опилок древесины хлоридами цинка и железа, приведенное в работе [20,21], позволило показать синергетический эффект их воздействия на структуру древесины в процессе карбонизации: увеличение удельной поверхности и появление магнитных свойств у карбонизованного образца. Можно предположить, что использование ферроцена с хлоридом цинка приведет к дополнительному инициированию процессов замещения в ароматических структурах, содержащихся в лигниноцеллюлозном полимере и, соответственно, к новым структурным вариантам формирования продукта в процессе пиролиза.

Цель настоящей работы заключалась в создании новых композиционных материалов на основе древесины березы, модифицированной хлоридом цинка и ферроценом, а также в изучении влияния температуры на формирование пористой структуры получаемого твердого продукта.

\section{Экспериментальная часть}

В качестве исходного сырья использованы опилки древесины березы (ДБ) фракции менее 0,5 мм, которые модифицированы хлоридом цинка, а также хлоридом цинка и ферроценом методом пропитки. Весовое соотношение ДБ : $\mathrm{ZnCl}_{2}$ составляет $1: 1$, а ДБ: $\mathrm{ZnCl}_{2}: \mathrm{Fe}\left(\mathrm{C}_{5} \mathrm{H}_{5}\right)_{2}-1: 1: 0,1$. Большое содержание $\mathrm{ZnCl}_{2}$ в смеси обусловлено созданием продукта с высокой пористостью [16], а добавка небольшого количества ферроцена направлена на инициирование процессов полимеризации [6]. Полученные смеси при периодическом перемешивании высушены при $105^{\circ} \mathrm{C}$ до постоянного веса. Затем образцы карбонизованы на проточной установке в токе аргона при скорости нагрева $10^{\circ} \mathrm{C} /$ мин до температур 400 и $800{ }^{\circ} \mathrm{C}$ и отмыты в дистиллированной воде при непрерывном перемешивании на магнитной мешалке ( $\mathrm{T}=55^{\circ} \mathrm{C}, \tau=1,5$ ч). Высокотемпературный образец практически не растворяется в горячей воде, поэтому в дальнейших исследованиях использован неотмытый продукт.

Термический анализ образцов проведен на термоанализаторе STA 449 F1 Jupiter в среде аргона при скорости нагрева $10^{\circ} \mathrm{C} /$ мин. Электронно-микроскопические исследования выполнены на сканирующем электронном микроскопе S-5500 (Hitachi) со встроенным энергодисперсионным спектрометром для микрорентгеноспектрального анализа. Рентгеновские дифрактограммы сняты на рентгеновском дифрактометре ДРОН-3 в диапазоне углов $2 \theta$ от 5 до 70 градусов. Излучение $\mathrm{Cu}_{\mathrm{k} \alpha}$, шаг сканирования $-0,02$ град, время накопления в точке -1 сек. Удельная поверхность (БЭТ) образцов измерена на анализаторе удельной поверхности СОРБТОМЕТР-М. 


\section{Обсуждение результатов}

В таблице приведены данные по выходу и удельной поверхности твердых продуктов (ТП), полученных в процессе карбонизации исходной и модифицированной древесины. Как видно, добавка $\mathrm{ZnCl}_{2}$ в древесину приводит к росту выхода твердого продукта. Дополнительная водная обработка ТП, карбонизованного при $400{ }^{\circ} \mathrm{C}$, заметно уменьшает его выход, а обработка ТП, полученного при $800{ }^{\circ} \mathrm{C}$, практически не влияет.

Важно отметить также незначительное снижение выхода отмытого продукта, полученного при $400{ }^{\circ} \mathrm{C}$, а также неотмытого продукта, полученного при $800{ }^{\circ} \mathrm{C}$ из ДБ- $\mathrm{ZnCl}_{2}-\mathrm{Fe}\left(\mathrm{C}_{5} \mathrm{H}_{5}\right)_{2}$, что может быть вызвано влиянием ферроцена на процессы разложения образца.

Удельная поверхность существенно растет у модифицированных образцов, особенно у ТП, карбонизованного при температуре $400{ }^{\circ} \mathrm{C}$, после водной обработки. Более того, добавка ферроцена приводит к дополнительному росту удельной поверхности продукта, полученного при $800{ }^{\circ} \mathrm{C}$.

Таким образом, раскрытие пористой структуры ТП из модифицированных образцов происходит в основном за счет удаления водорастворимых веществ из низкотемпературных образцов и процессов пиролиза, протекающих при синтезе высокотемпературных образцов.

На рисунке 1 представлены результаты ДТГ немодифицированных и модифицированных образцов.

Динамика потери массы в процессе нагрева исходной древесины существенно отличается от убыли массы модифицированной древесины. Так, процесс интенсивного разложения исходной древесины протекает в области $300-400{ }^{\circ} \mathrm{C}$, при этом ее скорость разложения в 3 раза выше, чем скорость разложения модифицированной древесины. Более того, кривая ДТГ образца ДБ- $\mathrm{ZnCl}_{2}$ имеет два пика: при температурах 200 и $555^{\circ} \mathrm{C}$, а на кривой ДТГ ДБ- $\mathrm{ZnCl}_{2}-\mathrm{Fe}\left(\mathrm{C}_{5} \mathrm{H}_{5}\right)_{2}$ можно увидеть три основных пика убыли массы - при 200,580 и $750{ }^{\circ} \mathrm{C}$.

Выход и удельная поверхность твердого продукта, полученного из исходной и модифицированной древесины при температурах 400 и $800{ }^{\circ} \mathrm{C}$ до (1) и после (2) водной обработки

\begin{tabular}{l|c|c}
\hline \multicolumn{1}{c|}{ Образец } & Выход, мас.\% & Удельная поверхность, м $^{2} / \Gamma$ \\
\hline ДБ, $400{ }^{\circ} \mathrm{C}-1$ & 27,7 & менее 1,0 \\
ДБ, $400{ }^{\circ} \mathrm{C}-2$ & 27,7 & 6,0 \\
ДБ, $800{ }^{\circ} \mathrm{C}-1$ & 18,0 & 27,3 \\
ДБ- $\mathrm{ZnCl}_{2}, 400{ }^{\circ} \mathrm{C}-1$ & 52,5 & менее 1,0 \\
ДБ- $\mathrm{ZnCl}_{2}, 400{ }^{\circ} \mathrm{C}-2$ & 31,0 & 1099,8 \\
ДБ- $\mathrm{ZnCl}_{2}, 800{ }^{\circ} \mathrm{C}-1$ & 29,0 & 606,5 \\
ДБ- $\mathrm{ZnCl}_{2}-\mathrm{Fe}\left(\mathrm{C}_{5} \mathrm{H}_{5}\right)_{2}, 400{ }^{\circ} \mathrm{C}-1$ & 56,6 & 1,7 \\
ДБ- $\mathrm{ZnCl}_{2}-\mathrm{Fe}\left(\mathrm{C}_{5} \mathrm{H}_{5}\right)_{2}, 400{ }^{\circ} \mathrm{C}-2$ & 29,0 & 1113,8 \\
ДБ- $\mathrm{ZnCl}_{2}-\mathrm{Fe}\left(\mathrm{C}_{5} \mathrm{H}_{5}\right)_{2}, 800^{\circ} \mathrm{C}-1$ & 23,4 & 932,2 \\
\hline
\end{tabular}

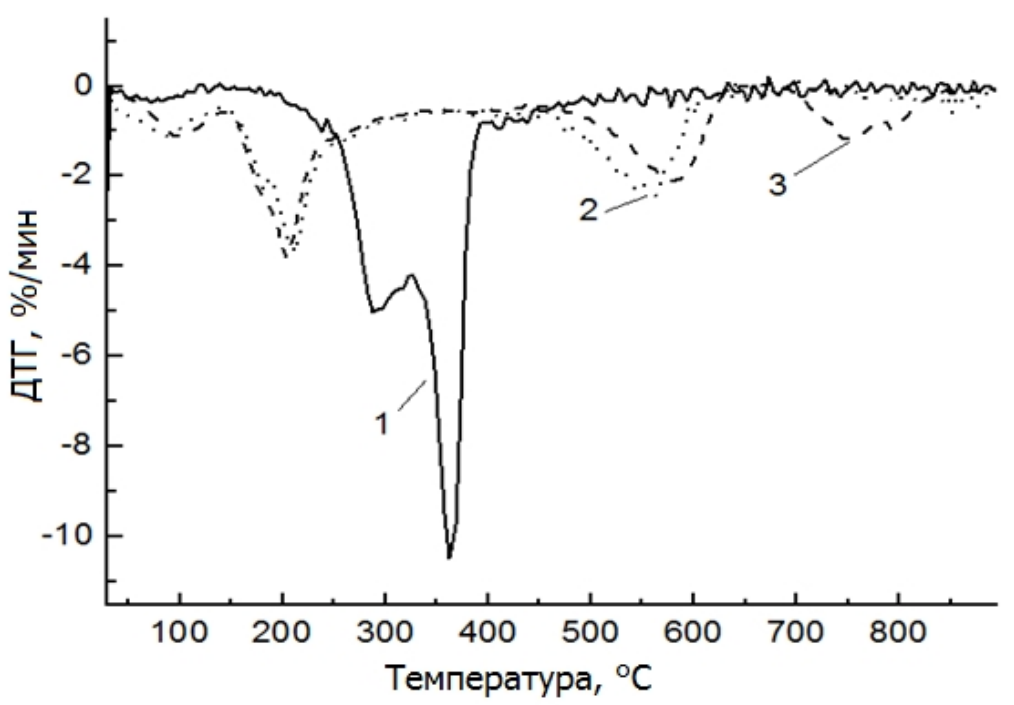

Рис. 1. Кривые ДТГ для образцов ДБ (1), ДБ- $\mathrm{ZnCl}_{2}$ (2) и ДБ- $\mathrm{ZnCl}_{2}-\mathrm{Fe}\left(\mathrm{C}_{5} \mathrm{H}_{5}\right)_{2}$ (3), снятые в токе аргона при скорости нагрева $10{ }^{\circ} \mathrm{C} / \mathrm{мин}$ 
Следовательно модификаторы, с одной стороны, смещают процессы разложения древесины в низкотемпературную область, с другой стороны, интенсифицируют процессы пиролиза в высокотемпературной области. Результаты ДТГ доказывают, что добавка ферроцена в образец приводит к дополнительной стадии интенсивного разложения образца в высокотемпературной области, которая может быть связана с процессами упорядочения структуры и удалением несопряженных с основной матрицей металлосодержащих фрагментов.

На рисунке 2 приведены дифрактограммы модифицированных твердых продуктов, карбонизованных при различных температурах.

Низкотемпературный ТП из ДБ- $\mathrm{ZnCl}_{2}$ имеет аморфную структуру со слабыми пиками $\mathrm{Zn}$ содержащей кристаллической фазы, наиболее близкой по структуре к симонколеиту (рис. 2a, кривая 1), которая после водной обработки четко проявляется на дифрактограмме $\left(\mathrm{Zn}_{5}(\mathrm{OH})_{8} \mathrm{Cl}_{2} \cdot \mathrm{H}_{2} \mathrm{O}, d=7,87 ; 5,35\right.$; 4,02 Å, 7-155) (рис. 2а, кривая 2). Рассеянное гало в области $25^{\circ}$ указывает на рентгеноаморфную структуру углерода в образце. На дифрактограмме высокотемпературного образца обнаруживаются слабые линии соединений цинка типа $\mathrm{ZnO}(\mathrm{d}=\mathrm{JCPDS}), \mathrm{ZnCO}_{3},\left(\mathrm{C}_{8} \mathrm{H}_{10} \mathrm{O}_{4}\right) \mathrm{Zn}$ и $\mathrm{C}_{3} \mathrm{H}_{6} \mathrm{O}_{3} \mathrm{Zn}$.

Добавка ферроцена в образец приводит к некоторым изменениям в дифракционной картине образца (рис. 2б). Так, дифракционные пики ТП, полученного при $400{ }^{\circ} \mathrm{C}$, принадлежат кристаллической фазе оксида цинка, которые четко проявляются после водной обработки образца, а наблюдаемые слабые дифракционные пики высокотемпературного образца свидетельствуют о наличии FeOCl. Образование фазы $\mathrm{FeOCl}$ в твердом продукте, по-видимому, вызвано редокс-процессами $\mathrm{Fe}^{2+} / \mathrm{Fe}^{3+}$, протекающими при пиролизе образца в высокотемпературной области, и удалением несопряженных с основной углеродной матрицей фрагментов, в том числе цинксодержащих.

На основании представленных данных можно сделать вывод, что в процессе водной обработки низкотемпературных ТП происходит удаление водорастворимых комплексов, включая металлосодержащие, вследствие чего раскрываются кристаллическая и пористая структуры образца. Следует отметить, что добавка в образец одного реагента - хлорида цинка приводит к образованию в основном гидроксохлорида цинка в ТП, а добавка двух модификаторов - хлорида цинка и ферроцена - к образованию оксида цинка и оксихлорида железа.

Представленные ниже СЭМ изображения модифицированных образцов показывают образование частиц различной формы на поверхности в зависимости от модификатора и температуры нагрева (рис. 3). Так, поверхность низкотемпературного образца из ДБ- $\mathrm{ZnCl}_{2}$ покрыта большими светлыми хлопьями и наноразмерными частицами, которые можно ассоциировать с гидроксохлоридом цинка (рис. 3a). На поверхности высокотемпературного образца можно обнаружить кристаллы $\mathrm{ZnO}$ в виде стержней (рис. 3б).
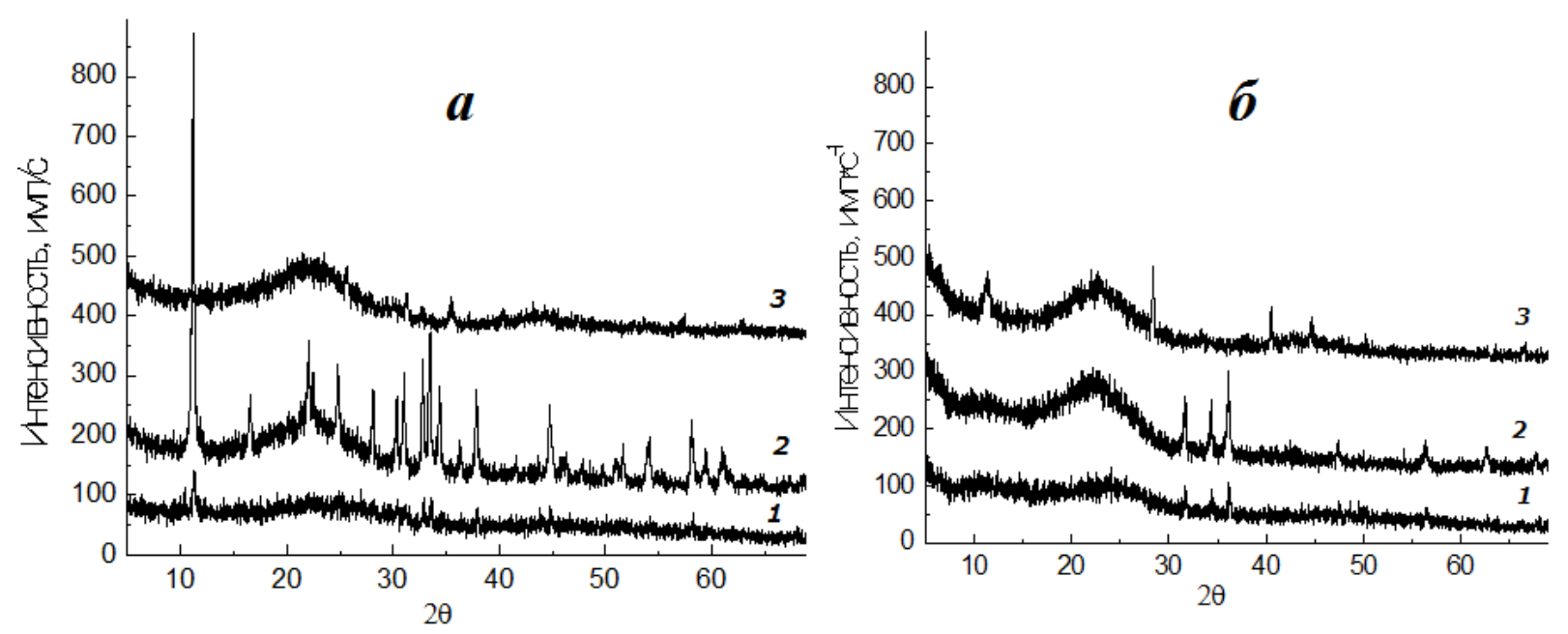

Рис. 2. Рентгенодифрактограмма твердых продуктов, полученных из ДБ- $\mathrm{ZnCl}_{2}(\mathrm{a})$ и ДБ- $\mathrm{ZnCl}_{2}-\mathrm{Fe}\left(\mathrm{C}_{5} \mathrm{H}_{5}\right)_{2}$ (б): $1-400{ }^{\circ} \mathrm{C}$ (без водной обработки), $2-400{ }^{\circ} \mathrm{C}$ (после водной обработки), $3-800{ }^{\circ} \mathrm{C}$ (без водной обработки) 
Поверхность образца, полученного при $400{ }^{\circ} \mathrm{C}$ из ДБ- $\mathrm{ZnCl}_{2}-\mathrm{Fe}\left(\mathrm{C}_{5} \mathrm{H}_{5}\right)_{2}$, покрыта нанодисперсными частицами практически регулярного размера (20-50 нм), на которой встречаются макрочастицы в виде усеченных шестигранных пирамид, основание которых в виде гексагона прикреплено к углеродистой поверхности (рис. 3в). Рост подобных кристаллитов, по-видимому, связан с координационным взаимодействием ферроцена с растущим радикалом, образующимся в процессе разложения лигниноцеллюлозной массы, который способствует повышению электроноакцепторных свойств растущего макрорадикала. Более того, его взаимодействие с ионом цинка приводит к образованию гексагональной формы частиц, подобных структуре оксида цинка. Можно сказать, что их образование происходит по механизму «живущей полимеризации» [22], основанному на целенаправленном изменении реакционной способности роста радикалов, т.е. в присутствии ферроцена обнаруживаются признаки наличия «живущих» центров роста цепи.

Морфология высокотемпературного образца совершенно другая: на монолитной углеродистой поверхности обнаружены частицы в виде стержней различной длины, которые, по-видимому, отражают структуру окисленного железа (рис. 3г).

Таким образом, структура твердых продуктов существенно зависит от температуры синтеза и неорганической составляющей. Причем добавка ферроцена в образец приводит к образованию на поверхности твердого продукта кристаллитов бо́льших размеров. Так, продукт, полученный из опилок древесины с $\mathrm{ZnCl}_{2}$ при $800{ }^{\circ} \mathrm{C}$, содержит кристаллиты $\mathrm{ZnO}$ в форме стержней, средний размер которых составляет $250 \times 60$ нм, а ТП, полученный из ДБ- $\mathrm{ZnCl}_{2}-\mathrm{Fe}\left(\mathrm{C}_{5} \mathrm{H}_{5}\right)_{2}$ при $400{ }^{\circ} \mathrm{C}$, содержит усеченные пирамидальные час-

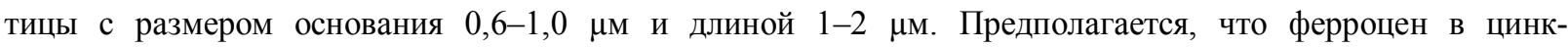
углеродистой структуре способствует координационному росту макромолекул в виде усеченных конусообразных гексагональных структур.
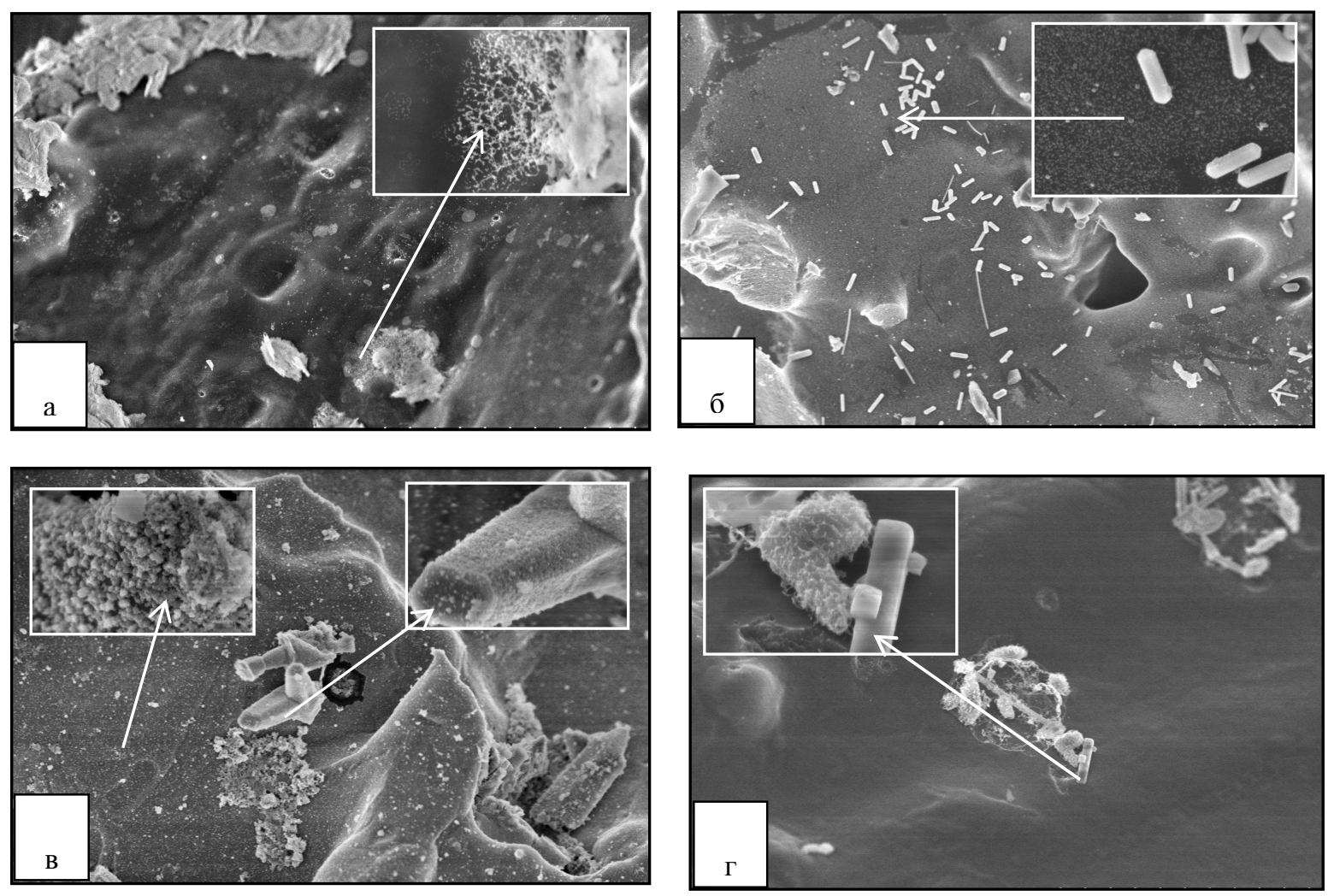

Рис. 3. СЭМ изображения образцов, полученных из ДБ- $\mathrm{ZnCl}_{2}$ при температурах $400{ }^{\circ} \mathrm{C}$ (а) и $800{ }^{\circ} \mathrm{C}($ б); ДБ- $\mathrm{ZnCl}_{2}-\mathrm{Fe}\left(\mathrm{C}_{5} \mathrm{H}_{5}\right)_{2}$ при $400{ }^{\circ} \mathrm{C}$ (в) и $800{ }^{\circ} \mathrm{C}$ (г)

\section{Bыводы}

1. Представлен метод получения пористых металл-углеродных композитов из древесины, модифицированной хлоридом цинка и ферроцена, и показано, что добавка ферроцена в исходный образец приводит к существенному изменению текстуры продукта и дополнительному увеличению его удельной поверхности. 
2. Установлено, что после водной обработки модифицированного твердого продукта, полученного при $400{ }^{\circ} \mathrm{C}$, заметно раскрывается пористая структура и четко проявляется кристаллическая структура ZnO.

3. Выявлено образование усеченных конусообразных гексагональных кристаллитов на поверхности продукта, карбонизованного при $400{ }^{\circ} \mathrm{C}$ из смеси опилок березы с хлоридом цинка и фероцена. Предполагается, что рост подобных кристаллитов обусловлен координационным взаимодействием ферроцена с лигниноцеллюлозной массой и ионом цинка.

\section{Список литературы}

1. Marsh H., Rodriguez-Reinoso F. Activated Carbon. Elsevier Ltd., 2006. 536 p.

2. Derbyshire F., Jagtoyen M., Andrews R., Rao A., Gullon I.M., Grulke E. Carbon materials in environmental applications // Chemistry and physics of carbon. New York, 2001. Vol. 27. Pp. 1-66.

3. Swarnalatha S., Ganesh K.A., Sekaran G. Electron rich porous carbon/silica matrix from rice husk and its characterization // Journal Porous Mater. 2009. Vol. 16. Pp. 239-245.

4. Kennedy L.J., Vijaya J.J., Kayalvizhi K., Sekaran G. Adsorption of phenol from aqueous solutions using mesoporous carbon prepared by two-stage process // Chemical Engineering Journal. 2007. Vol. 132. N1-3. Pp. 279-287.

5. Setianingsih T., Kartini I., Arryanto Y. Study of Structural Properties of Mesoporous Carbon From Fructose with Zinc Borosilicate Activator // J. Pure App. Chem. Res. 2014. Vol. 3. N3. Pp. 114-122.

6. Yamamoto A. Organotransition Metal Chemistry. New York, 1986. 455 p.

7. Mao X., Simeon F., Achilleos D. S., Rutledge G.C., Hatton T. A. Metallocene/carbon hybrids prepared by a solution process for supercapacitor applications // J. Mater. Chem. A. 2013. Vol. 1. Pp. 13120-13127.

8. Курбанов М.А., Сулейманов Г.З., Сафаров Н.А., Гочуева А.Ф., Оруджев И.Н., Мамедова З.М. Эффект фотогашения электропроводности в композитах полимер - ферроцен // Физика и техника полупроводников. 2011. T. 45. №4. C. 510-517.

9. Skeika T., Zuconelli C.R., Fujiwara S.T., Pessoa C.A. Preparation and electrochemical characterization of a carbon ceramic electrode modified with ferrocenecarboxylic acid // Sensors. 2011. Vol. 11. Pp. 1361-1374.

10. Takahashi S., Anzai J. Recent progress in ferrocene-modified thin films and nanoparticles for biosensors // Materials. 2013. Vol. 6. Pp. 5742-5762.

11. Vijayvargiya R., Aks B., Nema A.K. Photo and biodegradation performance of polypropylene blended with photodegradable additive ferrocene (Part - I) // Int. Journal of Applied Sciences and Engineering Research. 2014. Vol. 3, N1. Pp. 153-170.

12. Mamane V. Metal-Catalyzed Cross-Coupling Reactions for Ferrocene Functionalization: Recent Applications in Synthesis// Material Science and Asymmetric Catalysis. 2008. Vol. 5. Pp. 303-312.

13. Westwood J., Coles S., Collinson S.R., Gasser G., Green S.J., Hursthouse M.B., Light M.E., Tucker J.HR. Binding and electrochemical recognition of barbiturate and urea derivatives by a regioisomeric series of hydrogen-bonding ferrocene receptors // Organometallics. 2004. Vol. 23, N5. Pp. 946-951.

14. Gasser G., Bond A.M,, Graham B., Kosowski Z., Spiccia L. Synthesis of new metal complex-biomolecule hybrids as redox sensors for specific nucleobases // NSTI Nanotech. 2005. Vol. 1. Pp. 8-12.

15. Yu C.J., Wang H., Wan Y., Yowanto H., Kim J.C., Donilon L.H., Tao C., Strong M., Chong Y.J. 2'-Ribose-ferrocene oligonucleotides for electronic detection of nucleic acids // Org Chem. 2001. Vol. 66 (9). Pp. 2937-2942.

16. Фенелонов В. Б. Введение в физическую химию формирования супрамолекулярной структуры адсорбентов и катализаторов. Новосибирск, 2002. 414 с.

17. Chang B., Wang Y., Pei K., Yang S., Dong X. $\mathrm{ZnCl}_{2}$-activated porous carbon spheres with high surface area and superior mesoporous structure as an efficient supercapacitor electrode // RSC Adv. 2014. Vol. 4. Pp. 40546-40552.

18. Цыганова С.И., Мельников А.Н., Королькова И.В., Чесноков Н.В., Кузнецов Б.Н. Получение пористых углеродных материалов из модифицированных $\mathrm{ZnCl}_{2}$ опилок березы // Журнал прикладной химии. 2007. Т. 80, №6. C. 943-943.

19. Tsyganova S.I., Korol'kova I.V., Chesnokov N.V., Kuznetsov B.N. Formation of the Porous Structure of Carbon Materials during Carbonization of Microcrystalline Cellulose Modified by Phosphoric Acid // Russian Journal of Bioorganic Chemistry. 2011. Vol. 37, N7. Pp. 809-813.

20. Tsyganova S.I., Bondarenko G.N., Korol'kova I.V., Fetisova O.Yu., Kargin V.F., Velikanov D.A. Synthesis of a highly porous carbon material with magnetic properties // Russian Journal of Applied Chemistry. 2011. Vol. 84, N12. Pp. 2131-2136.

21. Tsyganova S.I., Zhizhaev A.M., Mikhlin Yu.L, Patrushev V.V., Bondarenko G.N., Korol'kova I.V. Effect of the synthesis temperature of porous carbon-metal oxide composites on the gold particle morphology // Russian Journal of Physical Chemistry A. 2014. Vol. 88, N10. Pp. 1762-1766.

22. Korolev G.V., Marchenko A.P. Living-chain radical polymerization // Russian Chemical Reviews. 2000. Vol. 69, N5. Pp. 409-434. 
Tsyganova S.I.*, Zhizhaev A. M., Bondarenko G.N., Fetisova O.Y. SYNTHESIS OF THE POROUS METALCARBON MATERIALS BASED ON THE BIRCH WOOD MODIFIED WITH ZINC CHLORIDE AND FERROCENE

Institute of Chemistry and Chemical Technology SB RAS, Akademgorodok, 50/24, Krasnoyarsk, 660036 (Russia), e-mail: light@icct.ru

The synthesis of the porous metal-carbon materials from a birch sawdust, zinc chloride and ferrocene was studied at different temperatures. It has been found that modifiers shift decomposition processes of wood to low-temperature region and intensify the process of pyrolysis to high-temperature region. Addition of ferrocene in sample leads to additional stage of intensive decomposition of sample at $750^{\circ} \mathrm{C}$.

Porous carbon products with high specific surface of $1100 \mathrm{~m}^{2} / \mathrm{g}$ were received during carbonization of samples, as one modifier $\left(\mathrm{ZnCl}_{2}\right)$, and two $\left(\mathrm{ZnCl}_{2}, \mathrm{Fe}\left(\mathrm{C}_{5} \mathrm{H}_{5}\right)_{2}\right)$, up to $400{ }^{\circ} \mathrm{C}$. Reduction of the specific surface of carbon product is observed when the carbonization temperature is $800{ }^{\circ} \mathrm{C}$, wherein the product of wood with $\mathrm{ZnCl}_{2}$ has surface area $606 \mathrm{~m}^{2} / \mathrm{g}$, and product of wood with additives of $\mathrm{ZnCl}_{2}$ and $\mathrm{Fe}\left(\mathrm{C}_{5} \mathrm{H}_{5}\right)_{2}-932 \mathrm{~m}^{2} / \mathrm{g}$. It was established that the disclosure of porous structure of products during carbonization of modified samples occurs mainly due to the removal of water-soluble substances of low-temperature products and high-temperature pyrolysis.

Special textural shapes of carbon product obtained from the modified raw materials with two reagents were detected. The addition of ferrocene to initial mixture leads to formation of truncated cone-shaped hexagonal crystallites on the composite surface carbonized at $400{ }^{\circ} \mathrm{C}$. It is supposed that the growth of the crystallites of low-temperature composite is due to coordinating interaction of ferrocene with ligninocellulose polymer and zinc ion.

Keywords: synthesis, porous metal-carbon material, birch wood, zinc chloride, ferrocene, morphology.

\section{References}

1. Marsh H., Rodriguez-Reinoso F. Activated Carbon. Elsevier Ltd., 2006, 536 p.

2. Derbyshire F., Jagtoyen M., Andrews R., Rao A., Gullon I. M., Grulke E. Chemistry and physics of carbon. New York, 2001, vol. 27, pp. 1-66.

3. Swarnalatha S., Ganesh Kumar A., Sekaran G. Journal Porous Mater. 2009, vol. 16, pp. $239-245$.

4. Kennedy L.J., Vijaya J.J., Kayalvizhi K., Sekaran G. Chemical Engineering Journal. 2007, vol. 132, no. 1-3, pp. 279-287.

5. Setianingsih T., Kartini I., Arryanto Y. J. Pure App. Chem. Res. 2014, vol. 3, no. 3, pp. 114-122.

6. Yamamoto A. Organotransition Metal Chemistry. New York, 1986, 455 p.

7. Mao X., Simeon F., Achilleos D.S., Rutledge G.C., Hatton T.A. J. Mater. Chem. A. 2013, vol. 1, pp. 13120-13127.

8. Kurbanov M.A., Sulejmanov G.Z., Safarov N.A., Gochueva A.F., Orudzhev I.N., Mamedova Z.M. Fizika i tehnika poluprovodnikov. 2011, vol. 45, no. 4, pp. 510-517. (in Russ.).

9. Skeika T., Zuconelli C.R., Fujiwara S.T., Pessoa C.A. Sensors. 2011, vol. 11, pp. 1361-1374.

10. Takahashi S., Anzai J. Materials. 2013, vol. 6, pp. 5742-5762.

11. Vijayvargiya R., Aks B., Nema A.K. Int. Journal of Applied Sciences and Engineering Research. 2014, vol. 3, no. 1, pp. $153-170$.

12. Mamane V. Material Science and Asymmetric Catalysis. 2008, vol. 5, pp. 303-312

13. Westwood J., J Coles S., Collinson S.R., Gasser G., Green S.J., Hursthouse M.B., Light M.E., Tucker J. Organometallics. 2004, vol. 23, no. 5, pp. 946-951.

14. Gasser G., Bond A.M., Graham B., Kosowski Z., Spiccia L. NSTI Nanotech. 2005, vol. 1, pp. 8-12.

15. Yu C.J., Wang H., Wan Y., Yowanto H., Kim J.C., Donilon L.H., Tao C., Strong M., Chong Y.J. Org Chem. 2001, vol. 66 (9), pp. 2937-2942.

16. Fenelonov V.B. Vvedenie $v$ fizicheskuju himiju formirovanija supramolekuljarnoj struktury adsorbentov $i$ katalizatorov. [Introduction to the physical chemistry of formation of supramolecular structure of adsorbents and catalysts]. Novosibirsk, 2002, 414 p. (in Russ.).

17. Chang B., Wang Y., Pei K., Yang S., Dong X. RSC Adv. 2014, vol. 4, pp. 40546-40552.

18. Cyganova S.I., Mel'nikov A.N., Korol'kova I.V., Chesnokov N.V., Kuznecov B.N. Zhurnal prikladnoj himii. 2007, vol. 80, no. 6, pp. 943-943. (in Russ.).

19. Tsyganova S.I., Korol'kova I.V., Chesnokov N.V., Kuznetsov B.N. Russian Journal of Bioorganic Chemistry. 2011, vol. 37, no. 7, pp. 809-813.

20. Tsyganova S.I., Bondarenko G.N., Korol'kova I.V., Fetisova O.Yu., Kargin V.F., Velikanov D.A. Russian Journal of Applied Chemistry. 2011, vol. 84, no. 12, pp. 2131-2136.

21. Tsyganova S.I., Zhizhaev A.M., Mikhlin Yu.L, Patrushev V.V., Bondarenko G.N., Korol'kova I.V. Russian Journal of Physical Chemistry A. 2014, vol. 88, no. 10, pp. 1762-1766.

22. Korolev G.V., Marchenko A.P. Russian Chemical Reviews. 2000, vol. 69, no. 5, pp. 409-434.

Received February 24, 2015

Revised October 7, 2015

\footnotetext{
* Corresponding author.
} 
